\title{
Frequency Evaluation and Design Optimization of Laced HP Gas Turbine Blade
}

\author{
Harinath SP' $\mathbf{S P}^{1}$ Vinayaka $\mathbf{N}^{2}$ \\ ${ }^{1}$ Design and Simulation Engineer, Kshipra Simulations Center of Excellence Research and Development, Bengaluru, 560091, Karnataka, \\ India \\ ${ }^{2}$ Assistant Professor, Department of Aeronautical Engineering, Nitte Meenakshi Institute of Technology, Yelahanka, Bengaluru, 560064,
} Karnataka, India

\begin{abstract}
Rotary blade design is an important research area due to its criticality in applications in turbo machinery like steam turbine, aero or land based gas engines. A small mistuning gives rise to stress development through mode localization under high speed rotating conditions. Various elements like shrouds, lacing wire and tie-bolts are used as blade interconnecting elements. In the present work lacing wire is used as blade interconnecting element and the research deals with comparative case studies of frequency evaluation for without lacing and with lacing blade configurations of a HP Gas Turbine rotor. The lacing wire adds required stiffness to obtain greater structural performance as it is more aerodynamic and feasible when compared to without lacing wires free standing blades. The HP blade length of turbine is optimized based on the stress and the frequency checks. The positioning of lacing wire at $3 / 4^{\text {th }}$ along the blade height of HP turbine blades and wire cross section considered is circular are considered for this research work. A Design of Experiments $(\mathrm{DOE})$ is carried out to optimize the dimensional parameter of the lacing wire. Assuming root of turbine blade is 100\% under fixity condition, the study involves critical parametric evaluations involved in achieving mechanical integrity in airfoil design and blade platform design. Mechanical Integrity involves frequency margin checks, stress checks, analysis of Campbell diagram, checks for gross yield stress and so on, for design and off-design conditions for a given stage efficiency of $83 \%$ in an ideal HP turbine of a gas turbine engine.
\end{abstract}

Keywords: Gas engines, lacing wire, HP Gas Turbine rotor, DOE, mechanical integrity, frequency margin, Campbell diagram

\section{Introduction}

Mechanical Integrity of gas turbine blades to the turbine rotor is the basic and most important criteria for all gas turbines. The blade provides stiffness against external steady and cyclic varying loads and contributes to the mechanical integrity. The prime significant task in rotary machines, such as turbo machinery is to bring about the finest possible structural performance by overcoming the effects due to gas bending and centrifugal forces upon additionally introducing circumferential blade interconnecting elements throughout the turbine stage rotors.

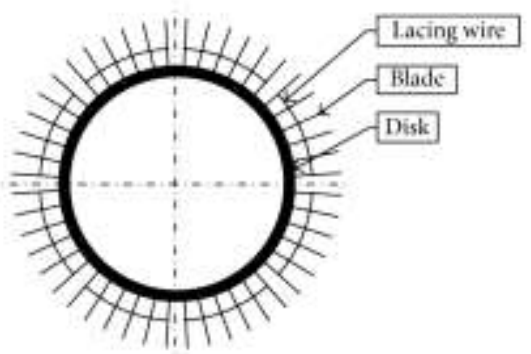

Figure 1: Schematic assembly of blade and disk with lacing wire

Since many decades, rotary engines are being used in applications to produce power with working mediums like water, steam, wind and gas. Incorporating a lacing wire as blade interconnecting element shown in figure 1 decreases the turbine blade dynamic stresses by a factor of 2 to 3 , when compared with stresses induced in without lacing wire free standing blade. A stable wire connection around the whole rotor stage is frequently applied to restrain axial turbine blades from harmonic and indeterminate excitations. Lacing wires during resonance generate considerable friction dissipation due to relative motions between the airfoil and lacing wire vibrations.

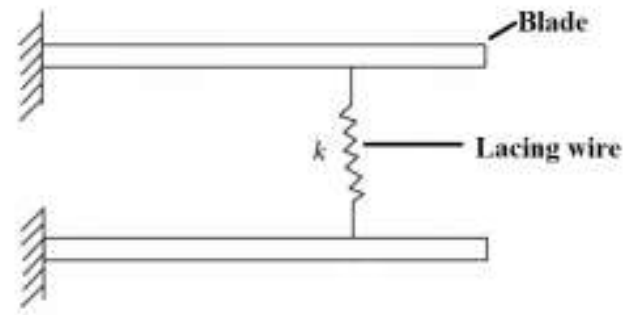

Figure 2: Lacing wire shown as springs

At rotating speeds, the turbine blades are subjected to yielding conditions like Elasto-Plastic and may reach to Fully-Plastic yielding. The centrifugal force induced due to this rotation acts along the blade height from its root hub to tip of the blade, and contributes to an approximately $85 \%$ to $90 \%$ frequency increase associated with blade torsion and bending modes of vibration, whereas the Coriolis coupling effects leads to other blade vibration modes. Turbine blades are modeled as rotating cantilever beams as shown in figure 2 with airfoil cross- section to study the vibration characteristics related to their dynamic behavior.

The work presented in this paper is to identify the best geometry and dimensional parameter of lacing wires positioned along the $3 / 4^{\text {th }}$ blade height for a HP stage rotor of a gas engine axial turbine.

\section{Problem Definition}

The Mechanical Integrity in bladed discs focuses on achieving the best airfoil through aero-structure interaction. 


\section{International Journal of Science and Research (IJSR) \\ ISSN (Online): 2319-7064}

Index Copernicus Value (2016): 79.57 | Impact Factor (2015): 6.391

As HP blades are slender blades, subjected to high wake flow excitations, temperature stresses and high alternating stresses in the end stages of the axial turbine of a gas turbine engine, the blades may bend at design and off-design conditions. This asks for the need to introduce structural members interconnecting blades for effective damping to avoid failure due to resonance. Customized methodology is ensured to achieve the best structural performance by introducing circular cross section lacing wires as blade interconnecting element at various locations along the blade.

\subsection{Objectives}

- To accomplish Mechanical Integration in airfoil design in gas turbines with smooth transition radius to minimize localized stresses.

- To study the importance of lacing wires in damping the blade working frequencies.

- Optimizing the turbine blade length with help of sectional stress and Campbell diagram.

- Optimization of dimensional parameter for the lacing wires.

- Analyze the HP blades for frequency separation margins with Campbell diagrams.

- To bring about a customized methodology for aerostructure interaction in circular cross-section laced blades for best structural performance.

\subsection{Design considerations}

The $100 \%$ operating speed chosen for the engine blade frequency evaluation is 8000rpm. Titanium alloy (Ti-6Al$4 \mathrm{~V}$ ) is chosen as the material for both blade and lacing wire, whose properties are listed in Table. 1 below:

Table 1: Shows material property

\begin{tabular}{|c|c|}
\hline Density & $4.43 \mathrm{E}-9$ Tones $/ \mathrm{mm}^{3}$ \\
\hline Young's modulus & $1.138 \mathrm{E} 5 \mathrm{MPa}$ \\
\hline Poisson's ratio & 0.342 \\
\hline Yield strength & $880 \mathrm{MPa}$ \\
\hline Co-efficient of thermal expansion & $9.7 \mathrm{e}-6 /{ }^{\circ} \mathrm{c}$ \\
\hline
\end{tabular}

Hub thickness is $5 \mathrm{~mm}$. Blade transition radius is $2.5 \mathrm{~mm}$. Factor of safety assumed is 1.68 , for allowable design stress of $522.6537 \mathrm{MPa}$. Separation margins assumed are left margin $5 \%$ and right margin $5 \%$ for the chosen operating speed, top 5\% and bottom 5\% in the Exciter Box. Mean diameter of the rotor is $260 \mathrm{~mm}$, number of blades is 30 , pitch of blades in the rotor is $61.8 \mathrm{~mm}$, stage efficiency is $83 \%$ and blade axial chord is $24.6 \mathrm{~mm}$. For over-speed testing assumed speed is $121 \%$ as per American Petroleum Institute (API) standards.

\section{Vibration characteristics of HP axial turbines with laced blades}

Axial turbines are the most crucial stage in gas turbine as its overall efficiency is what matters to obtain the required thrust and power from the engine. Axial turbine blades are subjected to high pressures and temperatures during the operation envelope. Hence, structural and overall performances of axial turbine blades play a vital role in a gas engine total performance. In rotating machinery blade design, the determination of blade natural frequencies is an important criterion, since blade failure due to fatigue occurs at resonant frequencies. Hence, study of vibration characteristics plays an important role in safe design of turbo-machines. The HP rotor blade excitations arise from components such as spline joints, blade interconnecting elements, nozzles, coupling bolts, etc. Therefore, engineers have to provide ample blade damping to obtain the required blade life.

In practice the technique used for the minimization of the vibratory stresses in gas turbine blades are to introduce dampers in the form of damping pins, damping wire or lacing wire. A hole is drilled through each blade airfoil and a wire is drawn through these holes which make the blade group stiffer, but there will also be slip between the wire and the blade, providing damping. Frictional forces are then active at the lacing wire outer surface and blade groove lacing contact surfaces and also at the interface along the length of the lacing wire where it talks to each other and hence provides maximum overall frictional damping.

Hence, in the present research lacing wires are chosen as blade interconnecting elements which provide sufficient blade damping. Introducing lacing wires in the blade decreases blade displacement and increases the natural frequencies, and the effect tends to become more predominant as the rotor running speed increases. The contact surface nature of the circular lacing wire will be a line contact in the blade lacing groove.

\section{Turbine Blade Modal Analysis and Frequency Separation Margin Evaluation}

The free standing blade behaves like a cantilever beam fixed at one end near the blade root and free at the other end near the blade tip. The first 5 modes namely 1 st bending, 1st flip, 1st torsion, 1st in-plane and 2nd flip are considered as critical vibration modes for frequency evaluation. The running speed harmonics i.e. $\mathrm{X}=(\mathrm{N} / 60)$, were $\mathrm{N}$ denotes rated $\mathrm{rpm}$ excitations up to $8 \mathrm{X}$ is considered as critical for the wake forces leaving the airfoil for the modal analysis.

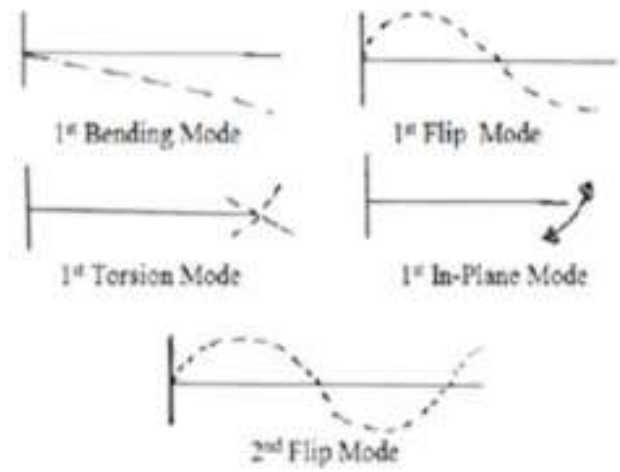

Figure 3: Modes shapes of blade

Figure 3 shows the mode shapes of a free standing turbine blade. Here, the disk mode participation is not considered for the present research. For this purpose Campbell diagram is 


\section{International Journal of Science and Research (IJSR) \\ ISSN (Online): 2319-7064 \\ Index Copernicus Value (2016): 79.57 | Impact Factor (2015): 6.391}

drawn at rated $8000 \mathrm{rpm}$ and over-speed conditions. Priority is given for the 1st Mode of turbine blade vibration due to the powerful excitations that come out for the first 6 engine orders. If sufficient separation margins are not achieved, the blade undergoes resonance and is subjected to high cycle fatigue. Hence, tuning of the initial modes with a high margin of safety becomes important. In rotary blades, the coupling between bending and torsion is induced by the lacing wires and the center of flexure is assumed to coincide with center of gravity. There is very less effect of the lacing wire on the blade in 1st torsion and 1st in-plane modes when compared to 1 st bending mode which shows considerable effect.

\section{Analysis for Optimum Blade Geometry}

Case 1: $70 \mathrm{~mm}$, blade model without a lacing wire is considered

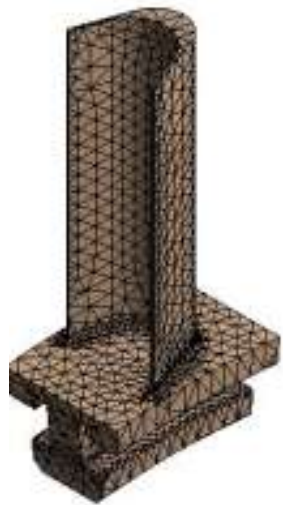

Figure 4: A mathematical model of $70 \mathrm{~mm}$ blade

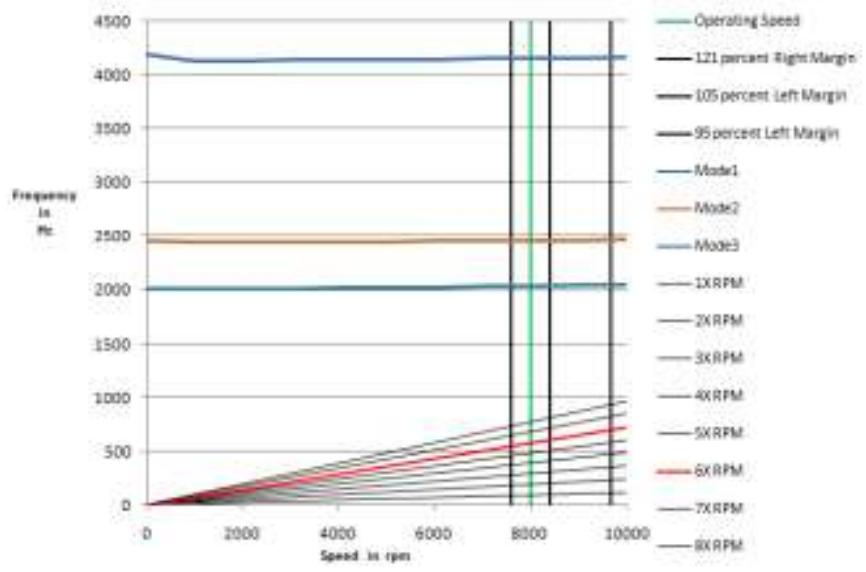

Figure 5: Campbell diagram for blade height of $70 \mathrm{~mm}$

Initially the HP blade considered was of 70mm blade height and based on the Campbell diagram results from Figure. 4; it shows that the first 8 excitations are very far from Mode 1 natural frequency. Hence, calling for a change in blade geometry as the blade is over-designed with higher FOS for design and off-design conditions.

\section{Case 2: Blade model without a lacing wire is considered}

By varying length of the blade considering the sectional stress and the frequency $120 \mathrm{~mm}$ height of the blade is considered as optimum for the present case. The justification of considering $120 \mathrm{~mm}$ blade height as optimum is given below:

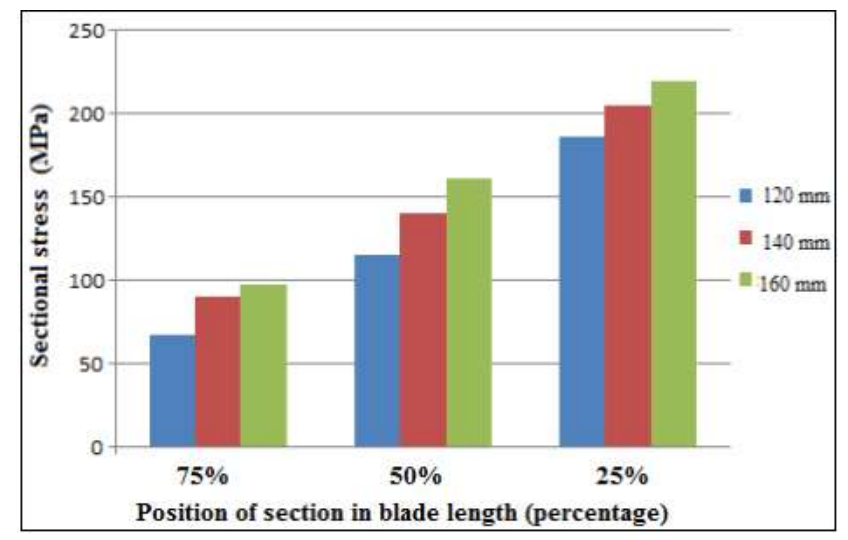

Figure 6: A graph plotted for section stress in blade

Above figure 6 shows a graph plotted for sectional stress for various heights of the blade and with varying length of the sectional plane. At $25 \%$ height i.e. bottom of the blade for $160 \mathrm{~mm}$ height blade has maximum stress and for $120 \mathrm{~mm}$ has the least when compare to all other heights. Hence, from stress point of view $120 \mathrm{~mm}$ of blade height is considered.

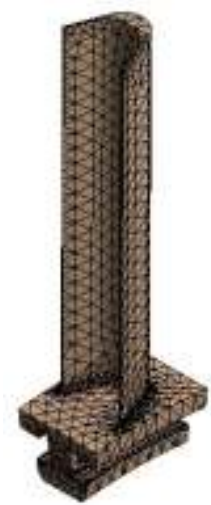

Figure 7: A mathematical model of $120 \mathrm{~mm}$ blade

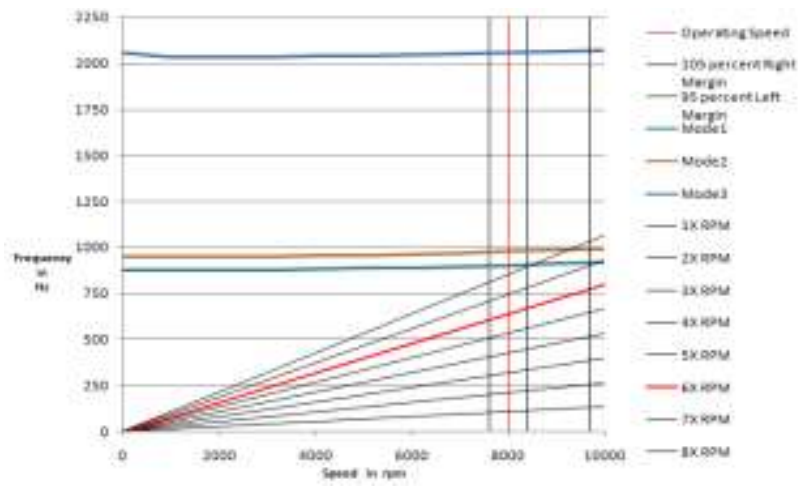

Figure 8: Campbell diagram for blade height of $120 \mathrm{~mm}$

Based on case 1 results, an approach was done to tune the blade frequency to a lesser FOS by incrementally increasing the blade height from $70 \mathrm{~mm}$ to $120 \mathrm{~mm}$, and the design was stopped at this blade height. The acceptability is well reflected in the Figure.8 for $120 \mathrm{~mm}$, calling for identification of best dimensional parameter of circular crosssection lacing wires, with wire at $3 / 4^{\text {th }}$ position along the HP turbine blade length. 


\section{International Journal of Science and Research (IJSR) \\ ISSN (Online): 2319-7064}

Index Copernicus Value (2016): 79.57 | Impact Factor (2015): 6.391

\section{DOE (Design of Experiments)}

Gas turbine rotors are often subjected to high transient and fluctuating speed loads. Many key parameters from design, material strength, geometry and behavior play a vital role in reliability and robustness during in-service condition. Sensitivity analysis and DOE become very essential to arrive at an optimum geometry. The design parameters and behavior constraints considered for the present work are to arrive at optimum dimensional geometry of the lacing wire through DOE which are given below:

- DOE is performed by maintain the height of the blade as $120 \mathrm{~mm}$.

- The stress of the blade should be within the allowable design limits.

- Allowable radial growth $\leq$ specified tolerance of $1 \mathrm{~mm}$.

- Allowable axial growth $\leq$ specified tolerance of $1 \mathrm{~mm}$.

A three best diameter of the circular cross-section is derived by following above method with specified constraints which is shown in the table below,

Table 2 Lacing wire Specification

\begin{tabular}{|c|c|}
\hline First diameter & $2.57 \mathrm{mn}$ \\
\hline Second diameter & $2.63 \mathrm{~mm}$ \\
\hline Third diameter & $2.71 \mathrm{~mm}$ \\
\hline
\end{tabular}

Case 3: $120 \mathrm{~mm}$ blade with lacing wire of diameter $2.57 \mathrm{~mm}$

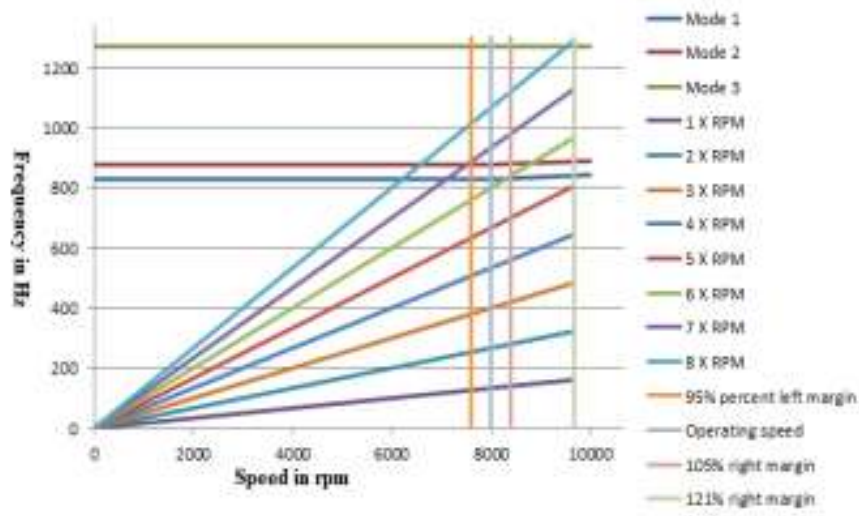

Figure 9: Campbell diagram for lacing wire of diameter $2.57 \mathrm{~mm}$

Case 4: $120 \mathrm{~mm}$ blade with lacing wire of diameter $2.63 \mathrm{~mm}$

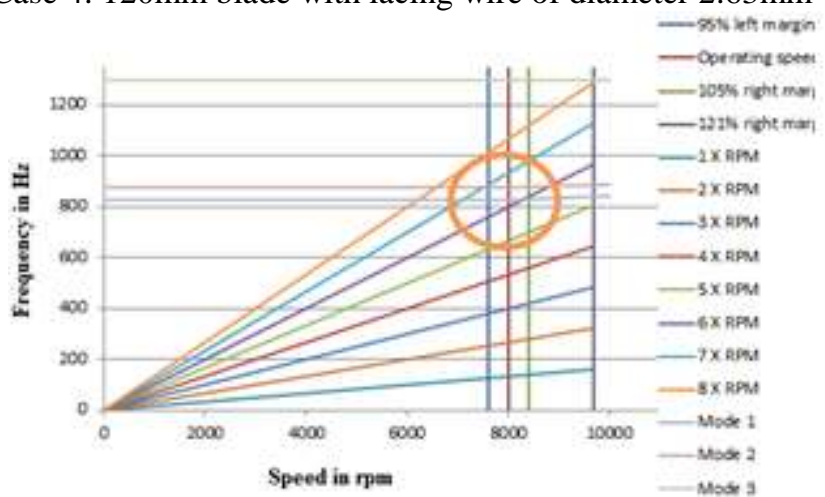

Figure 10: Campbell diagram for lacing wire of diameter $2.61 \mathrm{~mm}$
Case 5: $120 \mathrm{~mm}$ blade with lacing wire of diameter $2.71 \mathrm{~mm}$

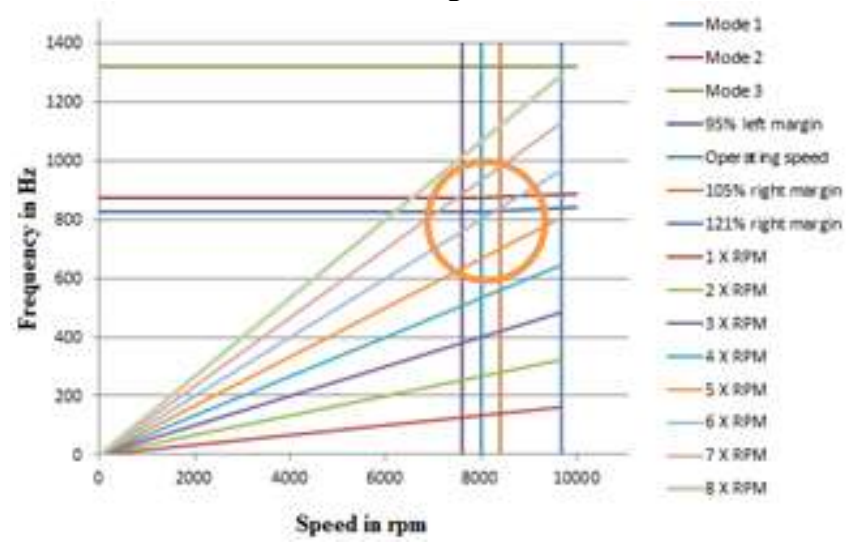

Figure 11: Campbell diagram for lacing wire of diameter $2.71 \mathrm{~mm}$

Comparing Campbell Diagram (CD) results from case 3 to case 5, i.e. Figures 9 to 11 , it clearly shows that all of the first 6 gas engine powerful excitations are safely passing with enough bandwidth without any resonance for the considered operating speed, separation margins and $121 \%$ over-speed condition. Another important observation to be made is that the case 4 and case 5 shows close proximity to each other results and are the desired test cases when compared to other test cases. The highlighted area in figure. 9 and figure .10 called as the Exciter Box justifies for the similarities in vibration characteristics of case 4 and case 5 . Hence, we arrive at the conclusion that the case 5 , i.e. blade with lacing wire at $3 / 4^{\text {th }}$ with circular diameter of $2.71 \mathrm{~mm}$ is the best optimum design configuration obtained out of the above 03 test cases considered as it is single laced with optimum desired vibration characteristics. The Exciter box is the area of prime importance which shows the frequency separation margins and mode excitations passing through it, which can be best analyzed in detail from figure 12.

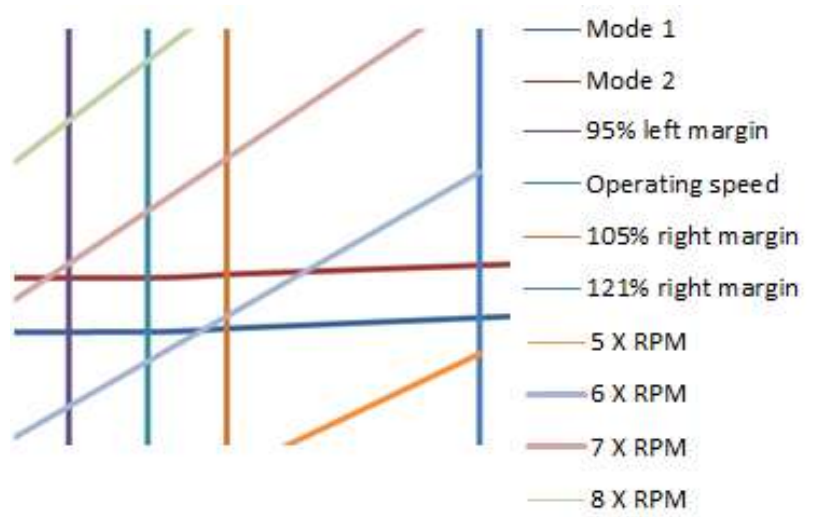

Figure 12: Exciter box for lacing wire of diameter $2.71 \mathrm{~mm}$

Figure. 12 is a detailed representation of the $5 \mathrm{X}, 6 \mathrm{X}, 7 \mathrm{X}$ and $8 \mathrm{X}$ frequency excitations passing over the modal frequencies in the considered operating speed range from $95 \%$ to $105 \%$, derived from Campbell diagram of Figure. 10. The above excitations are passing safely without any resonance in the considered separation margin regions for an operating speed of $8000 \mathrm{rpm}$ for both Mode 1 and Mode 2 frequencies. Usually in engineering practice, we check for $6 \mathrm{X}$ excitations resonance conditions; which is very much satisfied even in the $121 \%$ over-speed condition as per requirement of API

\section{Volume 6 Issue 12, December 2017}

\section{www.iisr.net}

Licensed Under Creative Commons Attribution CC BY 


\section{International Journal of Science and Research (IJSR) \\ ISSN (Online): 2319-7064}

Index Copernicus Value (2016): 79.57 | Impact Factor (2015): 6.391

standards for blade with lacing wire at $3 / 4^{\text {th }}$ with circular diameter of $2.71 \mathrm{~mm}$ case and is as shown in above Figure. 11.Thus, we have achieved an operating margin of $5 \%$ at left, $3 \%$ at right, $6 \%$ at top and $9 \%$ at bottom, as seen in the Exciter Box for Mode 1 for $8 \mathrm{X}$ excitation which is very much acceptable and confirms that blade with lacing wire at $3 / 4^{\text {th }}$ with circular diameter of $2.71 \mathrm{~mm}$ has no resonance.

\section{Conclusion}

1) Mechanical integration in airfoil design in gas turbines was achieved with a smooth transition radius of $2.5 \mathrm{~mm}$ to minimize localized stresses to $340.12 \mathrm{MPa}$ which is well within the gross yield strength.

2) By the means of Campbell diagram and the sectional stress checks the turbine blade model was optimized to $120 \mathrm{~mm}$

3) The lacing wire plays a vital role in blade frequency damping, and it is found that elliptical lacing wires provide better damping due to surface contact than circular lacing wires, where line contact exists in the airfoil cross-section along the blade height.

4) The best dimension for $120 \mathrm{~mm}$ blade model with lacing wire at $3 / 4^{\text {th }}$ position is $2.71 \mathrm{~mm}$.

5) From the Exciter Box, it concludes that the \% variations of frequencies for the considered test cases are less than $1 \%$ for zero speed, less than $2 \%$ for $50 \%$ load (4000 $\mathrm{rpm})$, less than $3.9 \%$ for $100 \%$ load $(8000 \mathrm{rpm})$ and less than $5.8 \%$ for $121 \%$ load $(9680 \mathrm{rpm})$ for an HP turbine stage blade.

\section{References}

[1] Tulsidas.D and M. Shantharaja, 2015. Effect of Taper and Twisted Blade in Steam Turbines. International Journal of Science Technology and Management, Vol.4(1), pp. 2394-1537.

[2] B.T. Lebele-Alawa, H.I. Hart, S.O.T.Ogaji and S.D. Probert, 2008.Rotor Blades profile influence on a gas turbine's compressor effectiveness. Journal of Applied Energy, Vol.85, pp.494-505.

[3] G.M.Chapman, E.Swain, X.Wang and M.Yang, 1992.Vibration Reduction of blading using Interconnecting Elements. Rotordynamics-1992, Proceedings of the International Conference on Rotating Machine Dynamics, Venice, Springer-Verlag London Limited, pp.270-277.

[4] A.L.Salama, M.Petyt, 1978. Dynamic Response of Packets of Blades by the Finite Element Method, Journal of Mechanical Design. Transactions of ASME, Vol.100, pp. 660-666.

[5] D.J.Ewins, 2010. Control of vibration and resonance in Aero engines and rotating machinery-An overview. International Journal of Pressure Vessels and Piping, Vol.87, pp.504 -510.

[6] V.A. Bazhenov, A.I. Gulyar, S.O. Piskunov and V.P. Andrievskii, 2013. Design Life assessment of the blade root of a Gas Turbine unit under thermo mechanical loading. Journal of Strength of Materials, Vol.45(3), pp. 329-339.
[7] S. Narasimha, G. Venkata Rao and S. Ramakrishna, 2009. Stress and Vibration Analysis of a Gas Turbine with a Cottage-Roof Friction Damper using Finite Element Method. 14th National Conference on Machines and Mechanisms (NaCoMM-09), NIT Durgapur, India, Paper ID: DVAMSN8, pp.316-324.

[8] Mahesh Shankar, K. Kumar and S.L. Ajit Prasad, 2010.T-root blades in a steam turbine rotor: A case study. Journal of Engineering Failure Analysis , Vol.17, pp.1205-1212.

[9] Wen-hu Huang, 1981. Free and Forced Vibration of Closely Coupled Turbomachinery Blades.AIAA Journal, Vol.19(7), pp.918-924.

[10] G.M.Chapman and X.Wang, 1988. Interpretation of Experimental and Theoretical Data for Prediction of Mode Shapes of Vibrating Turbocharger Blades. Journal of Vibration, Acoustics, Stress, and Reliability in Design, Transactions of ASME, Vol.110, pp.53-58.

[11] N.N: Magazine of Modern Power Systems. 1995, pp.49.

[12] M.M.Bhat , V.Ramamurti and C.Sujatha, 1996. Studies on the Determination of Natural Frequencies of Industrial Turbine Blades. Journal of Sound and Vibration, Vol. 196(5), pp.681-703.

[13]B.L.Jaiswal and S.K. Bhave,1994. Experimental Evaluation of Damping in a bladed disk model. Journal of Sound and Vibration, Vol.177(1), pp.111-120.

[14] A.L.Deak and R.D. Baird, 1963. A Procedure for Calculating the Packet Frequencies of Steam Turbine Exhaust Blades. Journal of Engineering for Power, Transactions of ASME, pp.324-329.

[15] Animesh Chatterjee, Mangesh.S.Kotambkar, 2015.Modal characteristics of turbine blade packets under lacing wire damage induced mistuning. Journal of Sound and Vibration, Vol. 343, pp.49-70.

[16] E.Poursaeidi, M.R.Mohammadi Arhani, 2010.Failure investigation of an auxiliary steam turbine. Engineering Failure Analysis, Vol.17, pp.1328-1336.

Volume 6 Issue 12, December 2017 